\title{
Melanoma specific Th1 cytotoxic T lymphocyte lines in Vogt-Koyanagi-Harada disease
}

\author{
Kazumi Norose, Akihiko Yano
}

\begin{abstract}
Aims/background-To determine the functional properties and cytokine production profiles of melanoma specific cytotoxic T lymphocytes (CTLs) induced from peripheral blood leucocytes of two patients with Vogt-Koyanagi-Harada disease (VKH).

Methods-Melanoma specific CTL lines were established by long term coculture with a human melanoma cell line (P-36). Cytotoxic activity against $\mathbf{P}-36$ was measured by ${ }^{51} \mathrm{Cr}$ release. The involvement of human leucocyte antigen (HLA) class I or class II molecules in the cytotoxicity of the CTL lines against P-36 was analysed using anti-HLA class I or anti-HLA class II monoclonal antibody (MAb). Surface molecules of CTL lines were analysed by flow cytometry using MAbs specific for CD4, CD8, CD16, CD25, CD56, HLA-DR, $T$ cell antigen receptor (TCR) $\alpha \beta$ and TCR $\gamma \delta$. Cytokine production and soluble interleukin 2 receptor (sIL-2R) secretion were determined by enzyme linked immunosorbent assays. mRNAs of cytokines were analysed using reverse transcription polymerase chain reaction (RT-PCR).
\end{abstract}

Results-CTLs showed strong cytotoxic activity against $\mathrm{P}-36$. The CTL activity of the cell lines against $P-36$ was inhibited by the anti-HLA-DR MAb, whereas the MAb specific for monomorphic determinants of HLA-A, B, and C failed to block lytic activity. Flow cytometry identified the following surface molecules: $\mathrm{CD4}^{+}, \mathrm{CD8}^{-}$, $\mathrm{CD16}^{-}, \mathrm{CD}^{+} 5^{+}, \mathrm{CD}^{-}, \mathrm{HLA}-\mathrm{DR}^{+}, \mathrm{TCR} \alpha \beta^{+}$, and TCR $\gamma \delta^{-}$. CTLs constitutively produced a high level of IL-6. IL-6 production and sIL-2R secretion of CTLs were enhanced when CTLs were stimulated with P-36. CTLs also produced high levels of interferon $\gamma$ (IFN- $\gamma$ ) and IL-2, but not IL-4. mRNAs of IL-2 and IFN- $\gamma$ were detected by RT-PCR in the CTLs.

Conclusions-Melanoma specific HLADR restricted T helper 1 (Th1) CTLs may play a role in the immunopathogenesis of VKH. (Br F Ophthalmol 1996;80:1002-1008)

Vogt-Koyanagi-Harada disease (VKH) is a systemic disorder that affects various organs that contain melanocytes. Immunopathological examination of eyes from patients with VKH has shown infiltration of numerous types of leucocytes, especially $\mathrm{T}$ lymphocytes, ${ }^{12}$ indicating that $\mathrm{VKH}$ is an immunogenic inflammation disorder. Melanocyte specific cytotoxic T lymphocytes (CTLs) are believed to be generated in $\mathrm{VKH}$ and to play an important role in disease manifestations. ${ }^{3}$ The frequency of melanocyte specific $T$ cells in the blood was relatively high in the blood from the patients with VKH. ${ }^{3}$ Many types of $T$ cells are contained in inflammatory tissues, such as the peripheral blood, the aqueous humour, and the uvea. Thus, identification of the subset of antigen specific CTLs involved in $\mathrm{VKH}$ is important. Examination of cloned $\mathrm{T}$ cells that react to melanocytes would help to identify this subset.

Cytokines are believed to play major roles in immune responses in uveitic eyes, ${ }^{14}$ primarily by regulating the diverse functions of lymphocytes and monocytes. The type of antigen specific immune response is determined by the secretion or preferential activation of subsets of $\mathrm{CD}^{+} \mathrm{T}$ cells. T helper 1 (Th 1 ), Th2, and Th0 cells secrete distinctive subsets of cytokines that are associated with different $\mathrm{T}$ cell functions. ${ }^{5}$

In the present study, we established cell lines of melanoma specific CTLs using peripheral blood leucocytes (PBLs) obtained from two patients with VKH for the purpose of studying cell functions, surface markers, and patterns of cytokine secretion in these cell lines.

\section{Materials and methods}

BLOOD DONORS

Two Japanese patients were admitted to the Department of Ophthalmology of the Shinshu University School of Medicine with blurred vision, central scotoma, metamorphopsia, photophobia, and severe headaches. VKH was diagnosed based on clinical symptoms and the results of a slit-lamp examination, ophthalmoscopy, fluorescein angiography, and laboratory analysis of cerebrospinal fluid. The patients had not been receiving systemic corticosteroids. The human leucocyte antigen (HLA) phenotypes of these patients were as follows: patient 1 (SF male; 42 years) HLA-A24, A31, B7, B54, C1, C7, DR1, DR4, DRw53, DQ5,
University School of

Medicine, Matsumoto 390, 
and DQ7; and patient 2 (TS male; 39 years) HLA-A24, B61, B62, Cw3, DR4, DR2, DRw53, DQ1, and DQ3. The control group consisted of six HLA-DR4 matched healthy volunteers (two men and four women; aged 44.7 (SD 6.3) years). The tenets of the Declaration of Helsinki were followed. Informed consent was obtained after the nature of the procedure was fully explained.

\section{TARGET CELLS}

The following cell lines were used in the cytotoxicity assays: a human melanoma cell line (P-36; SK-MEL-28; HLA phenotypes: HLAA11, A26, B40, DR4) originally established at the Memorial Sloan-Kettering Cancer Center (New York, USA) and a human cervical carcinoma cell line (HeLa-S3; HLA phenotypes analysed with polymerase chain reaction restriction fragment length polymorphism (PCR-RFLP) method: HLA-DRB1*0102/ 0102). Both cell lines were maintained in RPMI 1640 medium (Gibco, Grand Island, NY, USA) supplemented with $10 \%$ fetal calf serum (FCS; Gibco) and penicillin (100 U/ml) at $37{ }^{\circ} \mathrm{C}$ in an atmosphere of $5 \%$ carbon dioxide in $100 \%$ humidity.

ISOLATION OF PBLS AND ESTABLISHMENT OF CELI LINES

PBLs were isolated as described previously. ${ }^{3}$ In brief, PBLs were isolated from heparinised venous blood by Ficoll-Conray density centrifugation. They were washed three times with Hanks' medium and then suspended in RPMI 1640 medium supplemented with $10 \%$ FCS and penicillin $(100 \mathrm{U} / \mathrm{ml})$. PBLs were adjusted to a density of $1.0 \times 10^{6} \mathrm{cells} / \mathrm{ml}$ of medium supplemented with $5 \mathrm{U} / \mathrm{ml}$ of recombinant interleukin 2 (rIL-2) (Shionogi, Osaka, Japan). To propagate cell lines, mitomycin $\mathrm{C}$ treated P-36 cells were added to the culture medium to serve as the antigen. Growing CTLs were stimulated with the antigen weekly and fed with fresh medium supplemented with $5 \mathrm{U} / \mathrm{ml}$ of rIL-2, as needed, according to the growth rate of the culture ${ }^{67}$ Cultures were maintained under the above mentioned conditions.

MEASUREMENT OF CYTOTOXICITY AGAINST P-36 AND HELA-S 3

Details of the assay methods have been described elsewhere. ${ }^{3}$ In brief, $5 \times 10^{6}$ target cells in $0.5 \mathrm{ml}$ of RPMI 1640 medium supplemented with $10 \%$ FCS were incubated with $1.85 \mathrm{MBq}{ }^{51} \mathrm{Cr}$ (sodium chromate, specific activity $16.48 \mathrm{GBq} / \mathrm{mg}$; NEN Products, Boston, MA, USA) for 45 minutes at $37^{\circ} \mathrm{C}$, with occasional gentle shaking. To measure cytotoxicity in PBLs and cell lines, $5 \times 10^{4}$ labelled target cells in $0.2 \mathrm{ml}$ of the medium were placed in 96 well round bottomed microtitre plates (Nunclon, Roskilde, Denmark) at effector/ target $(E / T)$ ratios of 10:1 and 50:1 for PBLs and 5:1 and 25:1 for cell lines. Experiments were conducted in triplicate. Culture plates were incubated for 6 hours at $37^{\circ} \mathrm{C}$ in $5 \%$ car- bon dioxide and $100 \%$ humidity. The plates were then centrifuged at $170 \mathrm{~g}$ for 10 minutes. A $0.1 \mathrm{ml}$ volume of the supernatant fluid was extracted from each well, and the amount of radioactivity in those samples was counted with a well-type Packard scintillation counter. Specific ${ }^{51} \mathrm{Cr}$ release was calculated as follows: $(E-C) /(M-C) \times 100$, where $E=$ experimental, $\mathrm{C}=$ spontaneous, and $\mathrm{M}=$ maximum ${ }^{51} \mathrm{Cr}$ release by saponin. Cell viability was determined by the trypan blue dye exclusion method. PBLs obtained from six HLA-DR4 matched healthy controls were analysed in a similar manner.

The supernatants from the culture of the CTLs were added to ${ }^{51} \mathrm{Cr}$ labelled P-36 to investigate the cytotoxic activity of the soluble factors. The cytotoxic activity of the soluble factors in the supernatants was measured by the method described above.

To test the blocking effects of anti-HLA class I or anti-HLA class II monoclonal antibody (MAb), $50 \mu \mathrm{l}$ of the appropriately diluted $\mathrm{MAb}$ was mixed with ${ }^{51} \mathrm{Cr}$ labelled P-36 or HeLa-S3 target cells and effector cells in a 6 hour CTL assay. The $\mathrm{E} / \mathrm{T}$ ratios used were 50:1 for PBLs and 10:1 for cell lines.

\section{FLOW CYTOMETRIC ANALYSIS}

Flow cytometry of cell populations was performed in two colours with fluorescein isothiocyanate (FITC) or phycoerythrin (PE) conjugated MAbs against human leucocyte antigens. Preparations were incubated at $4^{\circ} \mathrm{C}$ and washed in phosphate buffered saline (PBS) (-) containing $1 \%$ bovine serum albumin (BSA) and $0.1 \%$ sodium azide. Samples were analysed with a FACScan flow analyser (BectonDickinson, Mountain View, CA, USA).

\section{ANTIBODIES}

MAbs specific for human $T$ cells and $T$ cell subsets were purchased from BectonDickinson (Sunnyvale, CA, USA), Ortho Diagnostic Systems (Raritan, NJ, USA), and T Cell Sciences (Cambridge, MA, USA). We used MAbs directed against the lineage markers CD4 (helper/inducer T lymphocytes), CD8 (cytotoxic/suppressor $\mathrm{T}$ lymphocytes), CD16 (natural killer (NK) cells), CD25 (IL-2R; activated T and B lymphocytes), CD56 (NK cells), HLA-DR (activated T lymphocytes, B lymphocytes, monocytes, and macrophages), $T$ cell antigen receptor (TCR) $\alpha \beta$ and TCR $\gamma \delta$.

The B33.1.3 MAb (IgG2a), which is specific for HLA-DR, was kindly provided by $\mathrm{Dr} P$ Bice, Jefferson Cancer Institute, PA, USA. The $\mathrm{W} 6 / 32 \mathrm{MAb}$ (IgG2a), which is reactive against monomorphic determinants of HLA-A, B, and $C$, was purchased from the American Type Culture Collection (ATCC, Rockville, MD, USA). MAbs were used in the ascites form purified by $50 \%$ ammonium sulphate precipitation and by passage through an $\mathrm{ABx}$ column (J T Baker Inc, Phillipsburg, NJ, USA).

The TCR V region of CTL cell lines was analysed with the Diversi-T $\alpha \beta$ TCR Screening Panel 1A (T Cell Sciences, Inc, USA). 
ENZYME LINKED IMMUNOSORBENT ASSAY

Serum samples were obtained from these patients and healthy controls by separating clotted whole blood by centrifugation at $\mathbf{3 0 0 0}$ rpm for 10 minutes. Supernatants of cell lines were collected on the third day of culture with or without antigen stimulation and stored at $-80{ }^{\circ} \mathrm{C}$ until assayed for cytokines and soluble II-2 receptors (sIL-2R). Commercially available double sandwich ELISA test kits were used to measure IL-2 (Otsuka, Tokyo, Japan), IL-4 (Amersham International, Bucks), IL-6 (Toray-Fuji Bionics, Tokyo, Japan), interferon (IFN)- $\gamma$ (Toray-Fuji Bionics), and sIL-2R (T Cell Diagnostics, Cambridge, MA, USA). Before IL-2 was assayed, anti-IL-2 MAb coated 96 well microplates were washed three times with Dulbecco's PBS $(-)$ containing $0.05 \%$ Tween 20 . A $200 \mu l$ amount of the samples or diluted standards was placed into each well and allowed to react overnight at $37^{\circ} \mathrm{C}$. After wells were washed three times, $100 \mu \mathrm{l}$ of rabbit anti-human II-2 polyclonal antibody was added and allowed to react for 2 hours at room temperature. Wells were again washed three times and $100 \mu \mathrm{l}$ of horseradish peroxidase conjugated goat anti-rabbit IgG antibody was added. After incubation, $100 \mu \mathrm{l}$ of the substrate solution ( $1 \mathrm{mg} / \mathrm{ml} o$-phenylenediamine) was added. The reaction was terminated by adding $100 \mu \mathrm{l}$ of $1.0 \mathrm{~N} \mathrm{H}_{2} \mathrm{SO}_{4}$. The final absorbance was measured at $490 \mathrm{~nm}$ using an ELISA autoreader (TOSO, Tokyo, Japan). The lowest detectable concentration of IL-2 was 5 $\mathrm{pg} / \mathrm{ml}$. IL-4, IL-6, IFN- $\gamma$, and sIL-2R were also measured by double sandwich ELISA test kits. The lowest detectable concentrations of IL-4, IL-6, IFN- $\gamma$, and sIL-2R were $3 \mathrm{pg} / \mathrm{ml}, 5 \mathrm{pg} / \mathrm{ml}$, $15 \mathrm{pg} / \mathrm{ml}$, and $85 \mathrm{U} / \mathrm{ml}$, respectively.

REVERSE TRANSCRIPTION POLYMERASE CHAIN REACTION (RT-PCR) FOR CYTOKINE MRNA CTL lines were cocultured with P-36 for 24 hours. An amount of $1 \times 10^{6}$ cells were harvested and total RNA was prepared by a single step guanidium isothiocyanate-phenolchloroform extraction method (TRIzol, Gibco BRL, Gaithersburg, MD, USA). Preparations of cDNAs and PCR for detection of IL-2 mRNA, IFN- $\gamma$ mRNA, and of glyceraldehyde3-phosphate dehydrogenase (GAPDH) mRNA were performed using a TaKaRa RNA PCR kit with AMV RTase (TaKaRa Shuzo Co, Kyoto, Japan). GAPDH DNA was amplified as a standard to ensure that cDNA concentrations in different reaction mixtures were approximately equal. PCR primers used were as follows: GAPDH sense primer 5'ACCACAGTCCATGCCATCAC-3' and antisense primer 5'-TCCACCACCCTGTTGCTGTA-3' 8 (Clontech Laboratories, Inc, Palo Alto, CA, USA); IFN- $\gamma$ sense primer 5' - ATGAAATATACAAGTTATATCTTGGCTTT-3' and antisense primer 5'-GATGCTCTTCGACCTCGAAACAGCAT-3' (Clontech Laboratories, Inc); IL-2 sense primer 5'CATTGCACTAAGTCTTGCACTTGTCA-3 and antisense primer 5'-CGTTGATATTGCTGATTAAGTCCCTG-3' (Clontech Laboratories, Inc). Reactions were incubated
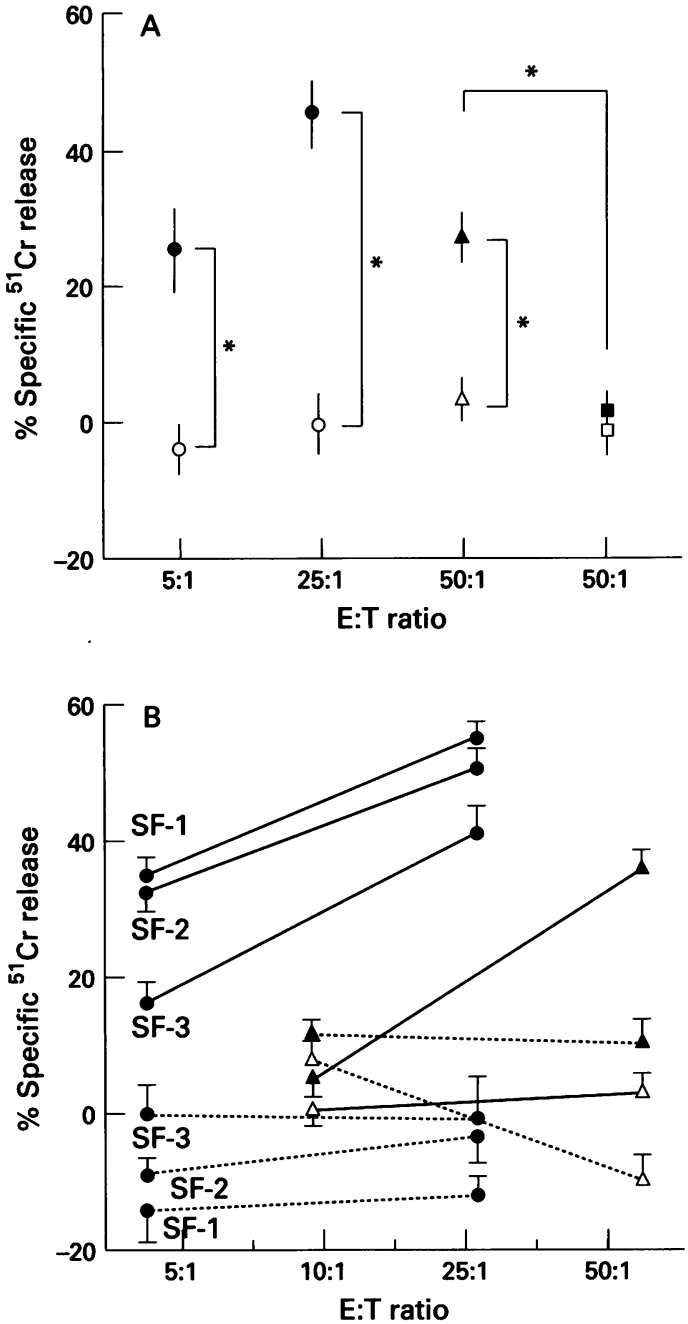

Figure 1 The cytotoxic activity of cytotoxic $T$ lymphocyte (CTL) lines against $P-36$. (A) The cytotoxic activity of the CTLs (circles) and peripheral blood leucocytes (PBLs) (triangle) obtained from the two patients with VKH and healthy controls (square) against P-36 (closed symbols) and $\mathrm{HeLa}-\mathrm{S} 3$ (open symbols) was examined by ${ }^{51} \mathrm{Cr}$ release assay. ${ }^{*} p<0.01$. (B) The cytotoxic activity of the representative $S F$ cell lines (SF-1, -2, and -3 ) (closed circles) and PBLs obtained from the patient (closed triangles) and of PBLs obtained from healthy controls (open triangles) against P-36 (-) and HeLa-S3 (-) was examined by ${ }^{31} \mathrm{Cr}$ release assay.

in a DNA thermal sequencer (Perkin Elmer Cetus, Norwalk, CT, USA) for 36 cycles. PCR products were run on a $1.2 \%$ agarose gel and stained with ethidium bromide.

\section{STATISTICS}

Data were shown as mean (SD) in the groups of more than three samples. Results were analysed using the two tailed Student's $t$ test, paired or unpaired as appropriate. A p value of 0.05 or less was considered significant.

\section{Results}

Melanoma specific six IL-2 dependent CTL lines were isolated from the blood of the patients with VKH. These cell lines showed strong cytotoxic activity against P-36 but not against HeLa-S3 (Fig 1A). Cell lysis was efficient even at an $E: T$ ratio of $5: 1$ and was specific for P-36. The representative data of cytotoxicity against P-36 of CTLs from patient 1 are shown in Figure 1B. P-36 specific cytotoxic activity was not observed in the PBLs from HLA-DR4 matched healthy volunteers. 


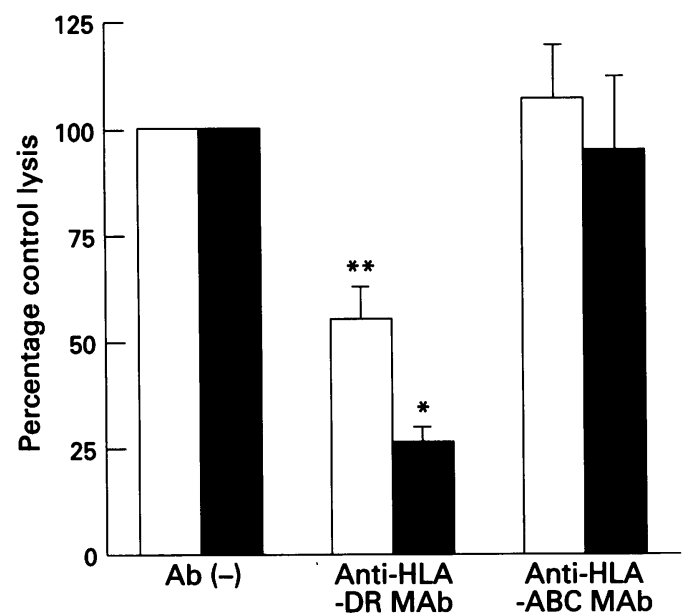

Figure 2 Inhibition of PBLs and SF-1 lysis by anti-HLA class II MAb. P-36 cells were exposed to SF-1 CTLs (solid column) or PBLs (open column) with the anti-HLA-DR $M A b$ (B33.1.3), the anti-HLA-A,B, and $C M A b$ (W6/32), or no $A b(A b(-))$. Data are expressed as percentage control lysis. Significant inhibition of cytotoxic activity of CTL lines $\left({ }^{*} p<0.01\right)$ and PBLs $\left({ }^{*} p<0.05\right)$ by anti-HLA-DR MAb was observed.
The CTL activity of these cell lines and PBLs against P-36 was inhibited by the anti-HLA-DR MAb (B33.1.3) (Fig 2) but not by the MAb (W6/32) specific for monomorphic determinants of HLA-A, B, and C. Thus, antigen recognition by these cell lines was restricted by HLA-DR molecules.

The supernatants from the culture of the cell lines stimulated with P-36 showed no cytotoxicity against $P-36$, even after 6 hours of in vitro culture (data not shown).

Flow cytometry showed that these cell lines were strongly positive for CD4, CD25, HLA$\mathrm{DR}$, and TCR $\alpha \beta$ surface molecules but negative for CD8 and TCR $\gamma \delta$ surface molecules (Fig 3). Cell lines were also negative for CD16 and CD56 (data not shown). No positive staining for $\beta$ V5(a), $\beta$ V5(b), $\beta V 8(a)$, $\beta V 12(a), \beta V 6(a), \alpha V 2(a)$, or $\alpha \beta V(a)$ TCRs was observed (data not shown).

These cell lines constitutively produced high levels of IL-6 (Table 1). IL-6 production and sIL-2R secretion were enhanced when CTL lines were stimulated with P-36. These cell
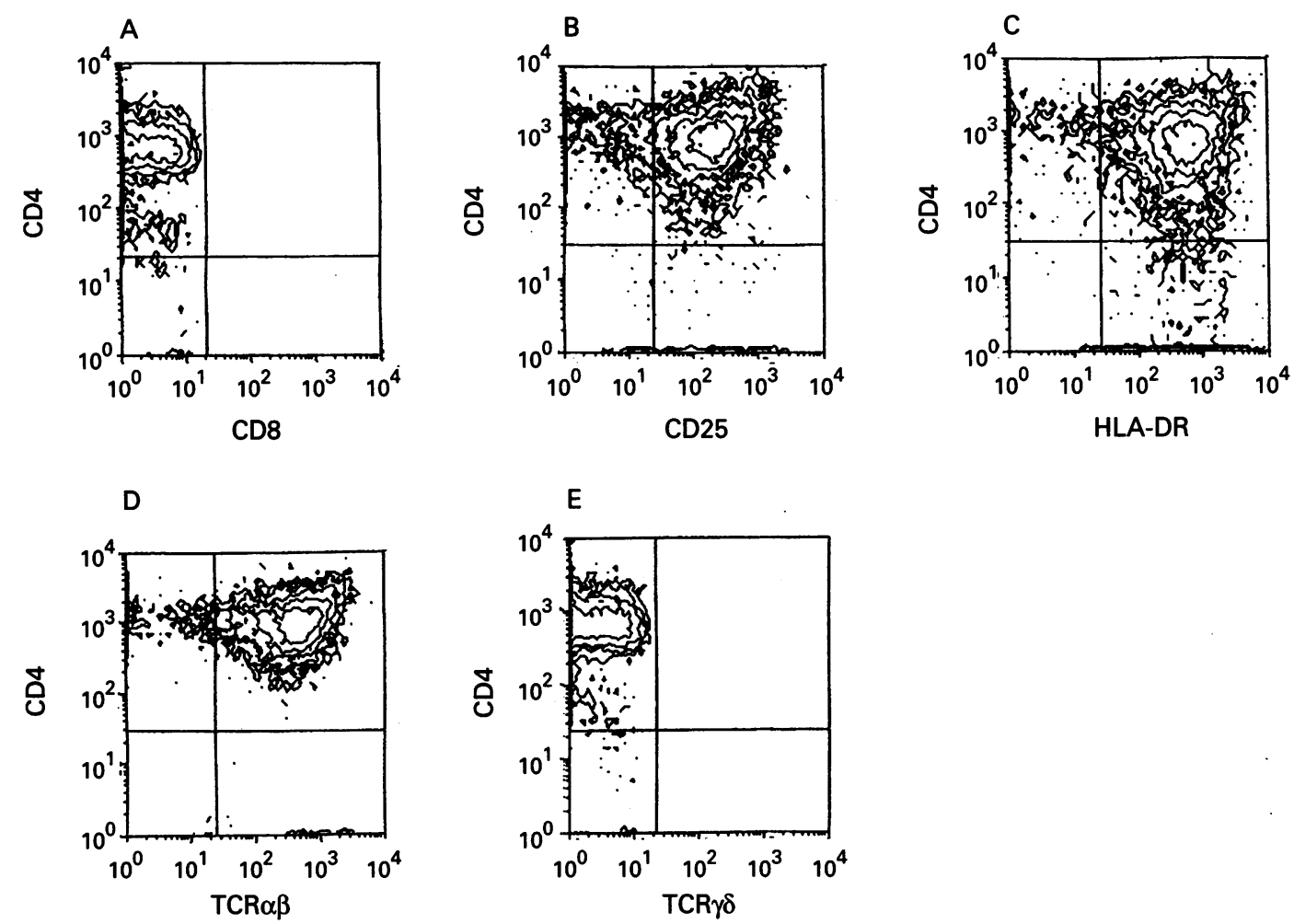

Figure 3 Flow cytometric analysis of a representative SF cell line (SF-1). SF-1 cells were stained with FITC conjugated anti-CD4MAb $(A, B, C, D, E), P E$ conjugated anti-CD8 MAb (A), PE conjugated anti-CD25 MAb $(B)$, $P E$-conjugated anti-HLA-DR MAb (C), PE conjugated anti-TCR $\alpha$ B MAb (D), and PE conjugated anti-TCR $\delta M A b$ (E).

Table 1 Cytokine production and sIL-2R secretion by $P-36$ specific $C D 4^{+} C D 8^{-}$CTL lines derived from two patients with Vogt-Koyanagi-Harada disease

\begin{tabular}{lllllll}
\hline Cell line & $\begin{array}{l}\text { P-36 } \\
\text { stimulation }\end{array}$ & $I F N-\gamma(p g / m l)$ & $I L-2(p g / m l)$ & $I L-4(p g / m l)$ & $I L-6(p g / m l)$ & $s I L-2 R(U / m l)$ \\
\hline SF (n=3) & - & $380(60)$ & $17.8(14.3)$ & $<3.0$ & $554.9(92.3)$ & $241.3(93.7)$ \\
& + & $456(226)$ & $12.6(15.7)$ & $<3.0$ & $2719.4(441.1)^{\star}$ & $1314.0(288.3)^{\star}$ \\
Fresh serum (patient SF) & & $<15.0$ & 15.9 & $<3.0$ & 5.7 & 341.0 \\
TS (n=3) & - & $320(48)$ & $11.5(4.4)$ & $<3.0$ & $756.2(64.1)$ & $482.2(55.9)$ \\
& + & $540(82)$ & $10.1(5.9)$ & $<3.0$ & $2461.0(394.6)^{\star}$ & $1579.0(382.4)^{\star}$ \\
Fresh serum (patient TS) & & $<15.0$ & 0.0 & $<3.0$ & 6.9 & 281.0 \\
Normal control sera & & $<15.0(\mathrm{n}=16)$ & $<5.0(\mathrm{n}=20)$ & $<3.0(\mathrm{n}=40)$ & $<5.0(\mathrm{n}=36)$ & $145-519(\mathrm{n}=275)$ \\
& & & &
\end{tabular}

Supernatants of SF line cells $\left(1.0 \times 10^{6}\right.$ cells $\left./ \mathrm{ml}\right)$ were harvested on the third day of culture with or without antigen stimulation.

Data were shown as mean (SD).

$\star$ Indicates $p<0.02$ compared with the cytokine production or sIL-2R secretion of CTL lines without P-36 stimulation. 


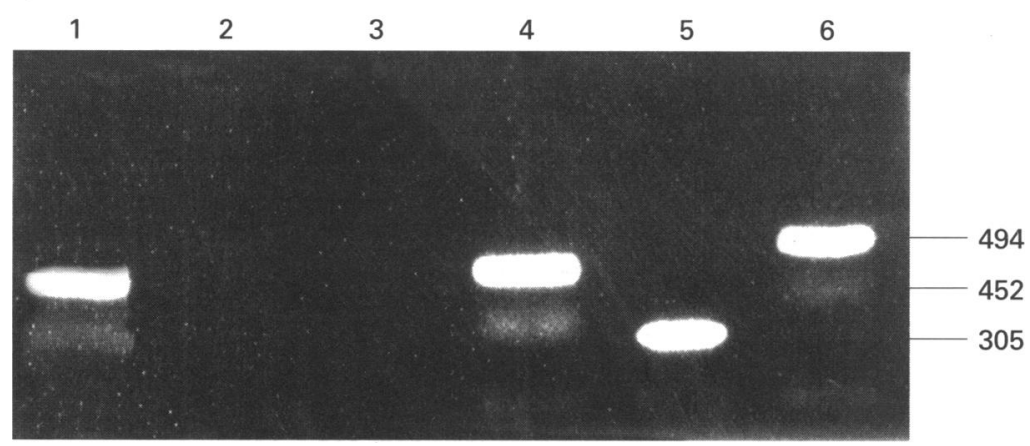

Figure 4 RT-PCR analysis of cytokine mRNA of SF-1 cells. Lanes 1 to 3, GAPDH,

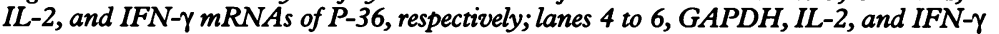
$m R N A s$ of SF-1 cells after 24 hours incubation with $P-36$, respectively. The molecular sizes of PCR products of IL-2, GAPDH, and IFN- $\gamma$ were 305, 452, and 494 base pairs, respectively.
These findings suggest that $\mathrm{CD}^{+}$CTLs predominate in the initial immunopathological responses in VKH.

The supernatants from $\mathrm{T}$ cell lines cultured with or without P-36 showed no cytotoxic activity against $\mathrm{P}-36$ in the present study (data not shown). The cytotoxic activity of $\mathrm{CD}^{+}$ CTLs has already been shown to be specific for P-36 as previously reported. ${ }^{31}$ Furthermore, the blocking effect of the anti-HLA-DR MAb was observed at 6 hour assay culture of effector (CTL) cells. These data strongly suggest that target P-36 cells were killed by $\mathrm{CD}^{+}$CTLs or the lines via direct contact but not via factor mediated or bystander killing. Mauri et al ${ }^{32}$ recently reported that $\mathrm{MHC}$ class $\mathrm{II}^{+} \mathrm{T}$ cell blasts or allogeneic $T$ cell blasts preferentially induce the development of antigen specific MHC class II restricted $\mathrm{CD}^{+}$cytotoxic effector cells. HLA-DR ${ }^{+}$CTL may act as antigen presenting cells. Thus, the anti-HLA-DR MAb may block such $T$ cell antigen presenting $T$ cell interaction as well as Th1 CTL P-36 interaction. Further experiments using a specific antiHLA-DR4 MAb and a specific-HLA-DR1 $\mathrm{MAb}$ to discriminate these possibilities are needed. We would have included an anti-HLADR4 MAb and an anti-HLA-DR1 MAb in the present experiments if they had been available.

Our previous study showed that the cytotoxic activity of PBLs from patients with VKH against ${ }^{51} \mathrm{Cr}$ labelled P-36 target cells was not inhibited when the unlabelled human $B$ cell line EBV-Wa (HLA phenotypes: HLA-A24, Bw54, DR4) was added to the assay culture. ${ }^{31}$ This suggests that CTLs induced in patients with VKH recognise the melanoma antigen presented by HLA-DR4 molecules of P-36 but not HLA-DR4 molecules on EBV-B lymphoma (EBV-Wa). S-antigen and interphotoreceptor retinoid binding protein (IRBP) have been shown to be antigenic molecules in patients with $\mathrm{VKH} .{ }^{33}$ If cultured human melanoma cells and normal melanocytes have common antigenic determinants or antigenically cross reactive components on their cell surfaces, then CTLs originally generated in patients with VKH would recognise such melanoma cells in vitro. P-36 has been shown to share surface antigens with normal adult melanocytes. ${ }^{34}$ Whether CTLs recognise a melanocyte specific antigen, and not a tumour antigen, has not been proved. Evidence that CTLs kill DR matched melanocytes or melanoma cells would provide confirmation of HLA-DR restriction of $\mathrm{CD4}^{+}$CTLs. Further studies are needed to determine the amino acid sequence of $T$ cell epitopes bound to HLADR4 molecules of P-36. Hirose et al ${ }^{35}$ established a cell line and clones of lymphocytes from a healthy donor, with specificity to $\mathrm{S}$-antigen. The need for distinctive culture conditions in which round bottom wells, high concentrations of antigen and extended incubation periods are used suggests that the cells which specifically respond towards S-antigen have low affinity and that these cells constitute a small proportion of PBLs in healthy donors. In this study, P-36 specific HLA-DR restricted $\mathrm{CD4}^{+}$CTL lines were not the aqueous humour of patients with acute phase endogenous uveitis (including $\mathrm{VKH}$ ) were primarily $\mathrm{CD}^{+}$HLA-DR ${ }^{+}$lymphocytes. ${ }^{30}$ 
established from the PBLs of HLA-DR4 matched healthy volunteers and HLA-DR4 unmatched patients with VKH (unpublished data).

Lymphokine activated killer (LAK) cells can be isolated as tumour specific killer cells from a tumour bearing host after selective expansion in vitro by culture in IL-2. We previously found no significant NK cell activity in PBLs from patients with $\mathrm{VKH}^{3}{ }^{3}$ The possibility that the CTLs used in the present study were LAK cells is ruled out for the following reasons: the cytotoxic activity of the CTLs to P-36 was blocked by MAbs specific for HLA-DR molecules in the present study; the CTLs have been cultured for more than 3 to 4 months, in contrast with the short term survival of LAK cells $^{36}$; and the surface markers of the CTLs are CD16 ${ }^{\circ}$ CD56-. Most LAK cells are believed to be NK cells and CD16 and CD56 molecules are believed to be the surface antigens of NK cells.

IFN- $\gamma$ is a potent multiple regulatory mediator of immune responses. Sakamoto et $a^{2}$ detected the HLA-DR antigen, which was not present in normal choroidal melanocytes, in choroidal melanocytes obtained from patients with VKH, suggesting that HLA-DR antigen expression is important in the initiation and/or perpetuation of immune reactivity in VKH. IFN- $\gamma$ induced not only HLA class I but also class II expression on human uveal melanoma cells in vitro. ${ }^{37}$ Upregulation of HLA-DR mRNA levels in P-36 cells induced by IFN- $\gamma$ was also confirmed by RT-PCR. ${ }^{38}$ IFN- $\gamma$ released by $\mathrm{CD}^{+}$CTLs in the inflammatory uvea in patients with $\mathrm{VKH}$ may induce expression of HLA-DR antigen on melanocytes, rendering them susceptible to $\mathrm{CD} 4^{+}$CTLs. These findings suggest that IFN- $\gamma$ may be a significant contributor to the immunopathophysiology of VKH. The role of HLA class II antigens (such as HLA-DR4) in the production of cytokines that activate particular $T$ cell subsets in VKH remains to be clarified.

In our previous study, ${ }^{1}$ no significant IL-2 production was observed in aqueous humour, serum, or cerebrospinal fluid obtained from patients with VKH. In the present study, the CTLs produced low levels of IL-2 even though they were stimulated by $\mathrm{P}-36$ in vitro and a high level of secretion of sIL-2R and a high density of CD25 molecules on the cell surfaces of the CTLs were detected during culture. The CTLs showed, however, a high level of IL-2 mRNA when they were stimulated by P-36 in vitro.

A further investigation of other mechanisms of cytotoxicity in the immunopathogenesis of VKH and further study of a comparison of cell lines from other individuals with $\mathrm{VKH}$ and from individuals with other types of uveitis are needed.

Supported in part by a grant in aid for scientific research from the Ministry of Health and Welfare, and by a grant from the Ministry of Education, Science, Sports and Culture, Japan.

1 Norose K, Yano A, Wang X-c, Tokushima T, Umihira J, Seki $A$, et al. Dominance of activated T cells and interleukin -6 in aqueous humor in Vogt-Koyanagi-Harada disease. Invest Ophthalmol Vis Sci 1994;35:33-9.

2 Sakamoto T, Murata T, Inomata H. Class II major histocompatibility complex on melanocytes of Vogt-Koyanagi-Harada disease. Arch Ophthalmol 1991;109:1270-4.

3 Norose K, Yano A, Aosai F, Segawa K. Immunologic analysis of cerebrospinal fluid lymphocytes in Vogt-Koyanagisis of cerebrospinal fluid lymphocytes in Vogt-Koyanagi-
Harada disease. Invest Ophthalmol Vis Sci 1990;31:1210-6. 4 De Vos AF, Hoekzema R, Kijlstra A. Cytokines and uveitis, a review. Curr Eye Res 1992;11:581-97.

5 Romagnani S. Human TH1 and TH2 subsets: regulation of differentiation and role in protection and immunopathology. Int Arch Allergy Immunol 1992;98:279-85.

6 Paul WE, Sredni B, Schwart RH. Long-term growth and cloning of non-transformed lymphocytes. Nature 1981;294 697-9.

7 Smith KA. Interleukin-2: inception, impact, and implications. Science 1988;240:1169-76.

8 Arcari P, Martinelli R, Salvatore F. The complete sequence of a full length CDNA for human liver glyceraldehyde-3phosphate dehydrogenase: evidence for multiple mRNA species. Nucleic Acids Res 1984;12:9179-89.

9 Braakman E, Rotteveel FTM, van Bleek G, van Seventer GA, Lucas CJ. Are MHC class II-restricted cytotoxic T lymphocytes important? Immunol Today 1987;8:265-7.

10 Jacobson S, Richert JR, Biddison WE, Satinsky A, Hartzman RJ, McFarland HF. Measles virus-specific T4 HLA antigens. F Immunol 1984;133:754-7.

11 Yasukawa M, Zarling JM. Human cytotoxic T cell clones directed against herpes simplex virus-infected cells. I. Lysis restricted by HLA class II MB and DR antigens. F Immunol 1984;133:422-7.

12 Krensky AM, Clayberger C, Reiss CS, Strominger JL, Burakoff SJ. Specificity of $\mathrm{OKT}^{+}$cytotoxic $\mathrm{T}$ lymphocyte clones. F Immunol 1982;129:2001-3.

13 Fleischer B. Acquisition of specific cytotoxic activity by human $\mathrm{T4}^{+} \mathrm{T}$ lymphocytes in culture. Nature 1984;308:365-7.

14 Hayward A, Boylston A, Beverley P. Lysis of $\mathrm{CD}_{3}$ hybridoma targets by cloned human CD4 lymphocytes. Immunology 1988;64:87-92.

15 Yang T-H, Aosai F, Norose K, Ueda M, Yano A. Enhanced cytotoxicity of IFN- $\gamma$-producing CD4 $4^{+}$cytotoxic T lymcytotoxicity of IFN- $\gamma$-producing $\mathrm{CD4}^{+}$cytotoxic T lymphocytes specific for $T$ gondii-in
cells. F Immunol 1995;154:290-8.

16 Vose BM, Bonnard GD. Human tumour antigens defined by cytotoxicity and proliferative responses of cultured lymphoid cells. Nature 1982;296:359-61.

17 Hersey P, MacDonald M, Schibeci S, Burns C. Clonal analysis of cytotoxic $T$ lymphocytes (CTL) against autologous melanoma: classification based on phenotypes, specificity and inhibition by monoclonal antibodies to $\mathrm{T}$ cell structures. $\mathrm{Can}$ cer Immunol Immunother 1986;22:15-23.

18 Darrow TL, Slingluff CL, Seigler HF. The role of HLA class $I$ antigens in recognition of melanoma cells by tumorspecific cytotoxic $T$ lymphocytes: evidence for shared tumor antigens. $\mathcal{F}$ Immunol 1989;142:3329-35.

19 Wölfel T, Klehmann E, Müller C, Schütt K-H, Meyer zum Büschenfelde K-H, Knuth A. Lysis of human melanoma cells by autologous cytolytic $\mathrm{T}$ cell clones: identification of human histocompatibility leukocyte antigen A2 as a restriction element for three different antigens. $\mathcal{F} \operatorname{Exp} M e d$ 1989;170:797-810.

20 Topalian SL, Soloman D, Rosenberg SA. Tumor-specific cytolysis by lymphocytes infiltrating human melanomas. $\mathcal{f}$ Immunol 1989;142:3714-25.

21 Storkus WJ, Zeh III HJ, Maeurer MJ, Salter RD, Lotze MT Identification of human melanoma peptides recognized by class I restricted tumor infiltrating T lymphocytes. F Immunol 1993;151:3719-27.

22 Kawakami Y, Zakut R, Topalian SL, Stötter H, Rosenberg SA. Shared human melanoma antigens: recognition by tumor-infiltrating lymphocytes in HLA-A2.1-transfected melanomas. F Immunol 1992;148:638-43.

23 Hom SS, Topalian SL, Simonis T, Mancini M, Rosenberg SA. Common expression of melanoma tumor-associated antigens recognized by human tumor infiltrating lymphocytes: analysis by human lymphocyte antigen restriction. I Immunother 1991;10:153-64.

24 Chen Q, Hersey P. MHC-restricted responses of $\mathrm{CD}^{+}$and $\mathrm{CD}^{+}$T-cell clones from regional lymph nodes of melanoma patients. Int $\mathcal{f}$ Cancer 1992;51:218-24.

25 Muul LM, Spiess PJ, Director EP, Rosenberg SA. Identification of specific cytolytic immune responses against autologous tumor in humans bearing malignan melanoma. F Immunol 1987;138:989-95.

26 Maccalli C, Mortarini R, Parmiani G, Anichini A. Multiple sub-sets of $\mathrm{CD4}^{+}$and $\mathrm{CD8}^{+}$cytotoxic T-cell clones directed to autologous human melanoma identified by directed to autologous human melanoma ider

27 Mochizuki M, Kuwabara T, McAllister C, Nussenblatt RB Gery I. Adoptive transfer of experimental autoimmune uveoretinitis in rats. Invest Ophthalmol Vis Sci 1985;26:1-9.

28 Atalla L, Linker-Israeli M, Steinman L, Rao NA. Inhibition of autoimmune uveitis by anti-CD4 antibody. Invest Ophthalmol Vis Sci 1990;31:1264-70.

29 McClellan KA, MacDonald M, Hersey P, Billson FA. VogtKoyanagi-Harada syndrome-isolation of cloned $T$ cells with specificity for melanocytes and melanoma cells. Aust NZ F Ophthalmol 1989;17:347-52.

30 Wang $X-c$, Norose $K$, Yano A, Ohta K, Segawa $K$. Two-color flow cytometric analysis of activated T lymphocytes in aqueous humor of patients with endogenous vs exogenous uveitis. Curr Eye Res 1995;14:425-33. 
31 Maezawa N, Yano A. Two distinct cytotoxic T lymphocyte subpopulations in patients with Vogt-Koyanagi-Harada disease that recognize human melanoma cells. Microbiol Immunol 1984;28:219-31.

32 Mauri D, Wyss-Coray T, Gallati H, Pichler WJ. Antigenpresenting $T$ cells induce the development of cytotoxic $\mathrm{CD4}^{+} \mathrm{T}$ cells. I. Involvement of the CD80-CD28 adhesion molecules. F Immunol 1995;155:118-27.

33 de Smet MD, Yamamoto JH, Mochizuki M, Gery I, Singh VK, Shinohara $\mathrm{T}$, et al. Cellular immune responses of patients with uveitis to retinal antigens and their fragments. patients with uveitis to retinal antigens

34 Houghton AN, Eisinger M, Albino AP, Cairncross JG, Old LJ. Surface antigens of melanocytes and melanomas: markers of melanocyte differentiation and melanoma subsets. $\mathcal{f}$ Exp Med 1982;156:1755-66.
35 Hirose S, McAllister CG, Mittal KK, Vistica BP, Shinohara $T$, Gery I. A cell line and clones of lymphocytes from a healthy donor, with specificity to S-antigen. Invest Ophthalmol Vis Sci 1988;29:1636-41.

36 Skibber JM, Lotze MT, Uppenkamp I, Ross W, Rosenberg SA Identification and expansion of human lymphokineactivated killer cells: implications for the immunotherapy of cancer. F Surg Res 1987;42:613-21.

37 Waard-Siebinga I de, Creyghton WM, Kool J, Jager MJ. Effects of interferon alfa and gamma on human uveal Effects of interferon alfa and gamma on human uveal

38 Yang T-H, Aosai F, Norose K, Ueda M, Yano A. Differential regulation of HLA-DR expression and antigen presentation in Toxoplasma gondii-infected melanoma cells by interleukin 6 and interferon $\gamma$. Microbiol Immunol 1996; 40:443-9.

m 